
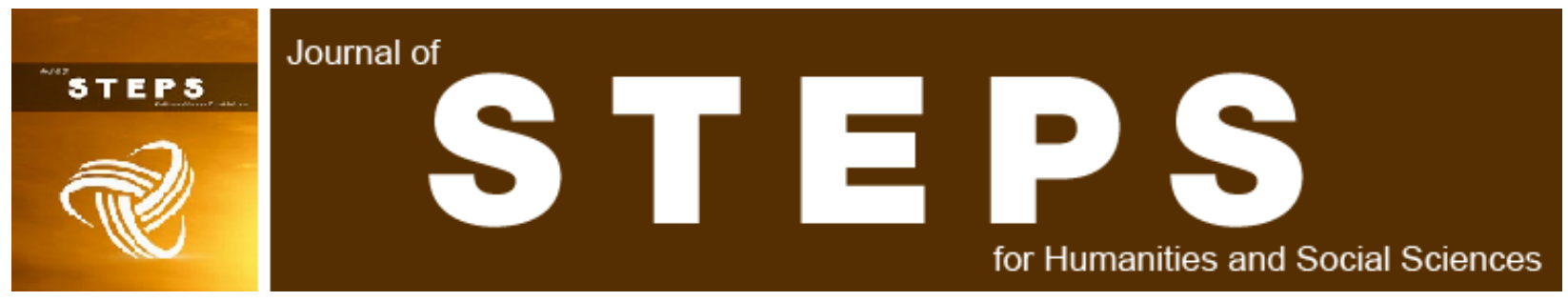

Volume 1 | Issue 1

Article 2

\title{
Synthesis essence in contemporary architectural production
}

\author{
Haidar Adnan Nsaif \\ University of Technology, Iraq, hk_kz@yahoo.com
}

Abdullah Salman

University of Technology, Iraq, abdullah.asadoon@yahoo.com

Follow this and additional works at: https://www.steps-journal.com/jshss

Part of the Education Commons

\section{Recommended Citation}

Nsaif, Haidar Adnan and Salman, Abdullah (2022) "Synthesis essence in contemporary architectural production," Journal of STEPS for Humanities and Social Sciences: Vol. 1 : Iss. 1 , Article 2.

Available at: https://doi.org/10.55384/2790-4237.1008

This Original Study is brought to you for free and open access by Journal of STEPS for Humanities and Social Sciences (STEPS). It has been accepted for inclusion in Journal of STEPS for Humanities and Social Sciences by an authorized editor of Journal of STEPS for Humanities and Social Sciences (STEPS). 
ماهية التوليف في النتاج المعماري المعاصر

$$
\text { عبد الله سعدون سلنان نصيف* * عبدرن }
$$

نادت العديد من الطروحات المعاصرة في جميع مجالات المعرفة الأنسانية بالتوليف كونه يمثل مفهوم

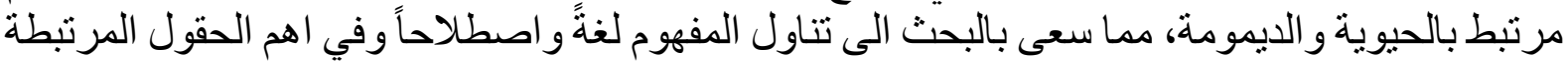

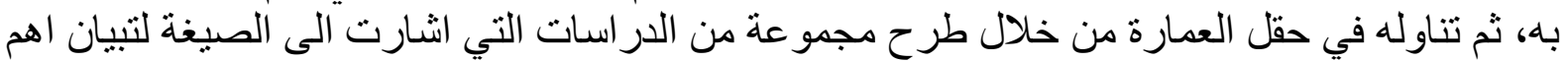

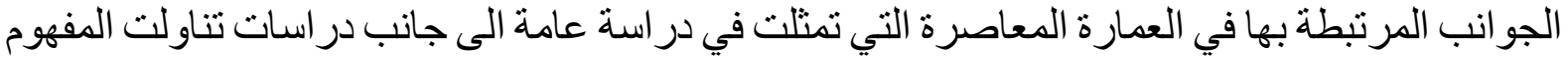
ضمن الحقب المعمارية المعاصرة (عمارة الحداثة، عمارة ما بعد الحداثة، العمارة العمارة التفكيكية، العمارة

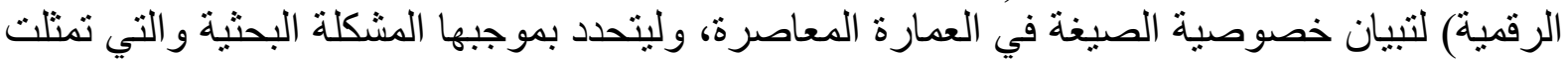

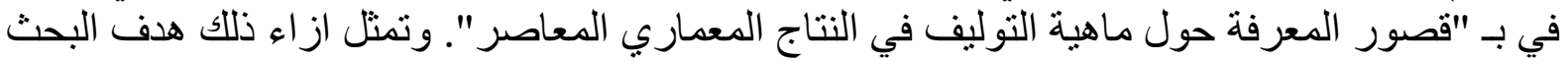

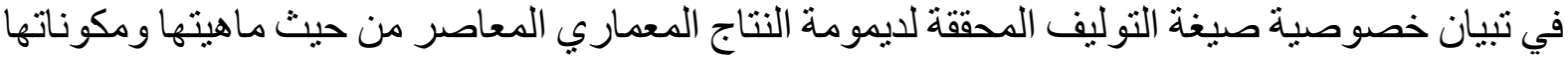

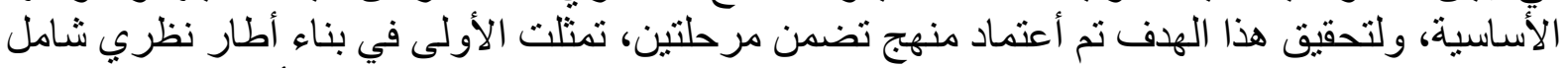

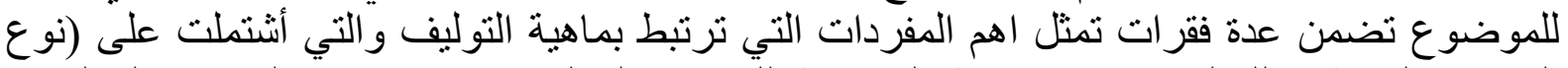

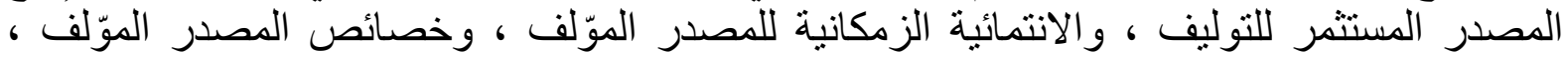

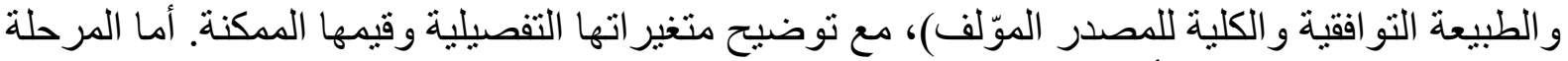

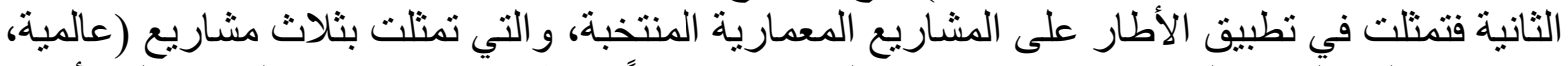

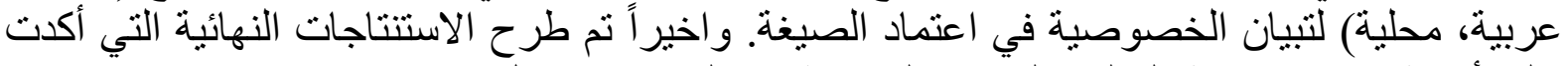

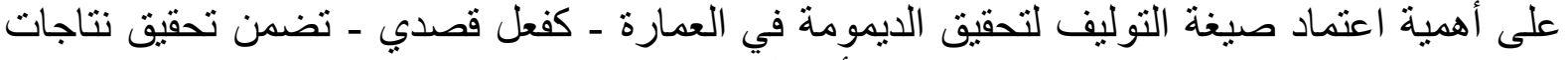

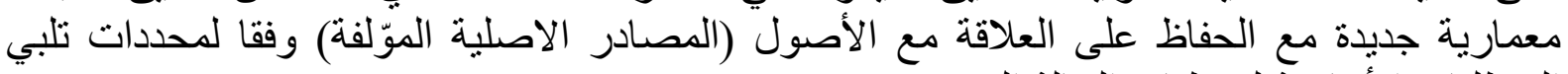




\title{
Synthesis essence in contemporary architectural production
}

\author{
Haidar Adnan Nsaif, University of Technology - Architecture, Baghdad, Iraq \\ Abdullah Saadoon Salman, University of Technology - Architecture, Baghdad, Iraq
}

\begin{abstract}
The research dealt with a crucial topic" Synthesis" in various fields of knowledge, that led the research to define the concept linguistically and idiomatically and in most important fields associated with it reaching to architecture, by presenting studies show most important aspects associated with it in contemporary architecture by a general study in addition to studies that dealt with the concept within the contemporary architectural eras (modern, postmodern, deconstructive, digital) architecture to show formula specificity in these eras, and to determine accordingly research problem, which was represented in "knowledge lack about synthesis essence in contemporary architectural production", And research aim was to clarify the specificity of the synthesis formula that achieved permanence of contemporary architectural production in terms of its essence and basic components. To achieve this goal, a two-stage approach was adopted. The first consisted in structuring a comprehensive theoretical framework included several items related to synthesis essence (Source type invested for synthesis, Spatiotemporal affiliation of the synthesized source, Synthesized source characteristics, Harmonic and total nature of the synthesized source), with an explanation of its possible values. The second stage was to apply the framework to elected architectural projects, which were represented by three projects (Foreign, Arab, local) to demonstrate formula specificity. Finally, Research emphasized the importance of adopting synthesis to achieve permanent in architecture - as an intentional act - that included new architectural products achievement while maintaining relationship with the assets (original sources synthesized) according to determinants that meet basic requirements of the new situation data.
\end{abstract}

Keywords: Synthesis, permanence, contemporary, architectural product. 


\section{Introduction}

Many contemporary literatures in all fields of human knowledge called for synthesis as it represents a concept linked to vitality and permanence and achieve connection with it in both its theoretical and practical aspects. It is considered one of the most important basic concepts advocated by contemporary propositions and called for its realization with everything that can represent a vital reality with which man interacts, until renewal and keeping pace with contemporary developments became a necessity for continuity.

The research was divided into three axes, the first of which concerned the introduction of the knowledge framework for synthesis concept in architecture through the presentation of linguistic and idiomatic definitions and in the fields, leading to architecture field to be dealt with a general study, in addition studies that dealt with within the contemporary architectural eras (modern, Postmodernism, deconstructive, digital) architecture to show the specificity of formula in contemporary architecture. But it turns out from the criticism of previous architectural studies that there are many knowledge gaps that prevented the formation of a clear conception of synthesis formula is in the contemporary architectural production, thus determining the research problem. While the second axis focused on building the items of theoretical framework, which included four main items related to the nature of the synthesis in the contemporary architectural production. Finally, the third axis dealt with the practical aspect by presenting selected projects for the practical study with discussion and analysis of the results that were drawn and putting forth the final conclusions.

\section{The first axis: the concept of synthesis in architecture}

This axis will illustrate synthesis concept definition, linguistically and idiomatically, and in many important related fields represented in art and cinema, leading to the field of architecture.

\subsection{Defining synthesis concept}

The concept of synthesis has been defined within the Arabic dictionaries to combine multiple similar or opposite meanings within a context that brings them together, as follows:

- To combine the two things: put them together, and to combine them in harmony, and it is also known as the overlaying of dissimilar things, their organization, or their harmonious grouping (www.almaany.com). 
- Parts coalition to each other, and the coalition of the whole in the context, even if there is a kind of contradiction or antithesis in some places (Omar, 2008, p 13).

In Addition, Synthesis was presented as a comprehensive physical or moral concept that includes several concepts, which are:

- Parts Synthesizing, or elements, in order to form a vision or system more complete (www.britannica.com).

- Synthesizing different ideas, influences, or things to form a different or new group (https://dictionary.cambridge.org).

The term "synthesis" has several meanings, the most important of which are:

- Composition or combining a group of parts or elements to form a whole (www.merriam-webster.com).

- Mixing different ideas, influences, or things to form a new or different group (https://dictionary.cambridge.org).

- Integrate often diverse concepts into a coherent whole (www.merriamwebster.com).

We conclude that the synthesis represents a comprehensive formula related to the material (physical) and moral (noticeable) aspects within multiple meanings, the most important of which is similarities combination or antagonisms or both and the overlap within a system or context that brings them together.

\section{2 synthesis concept in knowledge fields}

The concept of synthesis was introduced mainly within several fields, the most important of which is the field of art and cinema.

\subsubsection{Synthesis in art}

Synthesis in art represents the reconciliation of materials, whether they are of one species or multiple species, provided that the element of general acquisition occurs between them. No art is devoid of the ancient civilizations arts except that the synthesis has an echo in its production, as it is linked to the concepts that achieve permanence in the artwork and rooted in these civilizations 
(Alsaed, 2001, pp. 22-25). Griffith put forward the harmonic nature of synthesis by adopting compatibility or contradiction relations for the direct formal or for the structural or semantic aspects. Several trends emerged that reflect this formula, the most important of which is the organic or dialectical direction. Griffith depicts the process of synthesis in form of an organic structure (organism), and a great organic unit that includes within its divers (the idea of unity within diversity). For example, there are men and women, city and country, traditional and contemporary...etc., as these parts are adopted within their bilateral relations to form a relationship of contradiction or correspond. As for the dialectical trend, it appeared within the Soviet school in a formula that represents the unit as a cell that creates its own parts through cellular fission (in contrast to the organic trend that imagines it as a unit of assembly or merging of adjacent parts), and the opposition (contradiction relationship) between the parts is understood as the force The locomotive inner strength through which the unit is reconstituted as a new unit of another level on its formal, structural and even semantic level, and in this sense, the sum is reflected within each part, and each part reproduces the sum (Deleuze, 1997, p. 150-156).

We conclude from the above that synthesis formula is related to the essence of the properties invested from the original source, whether apparent or essential, in addition to the importance of adopting the compatibility nature of synthesis from relationships of compatibility or contradiction with the pluralistic nature of the synthesis, whether achieved from one or more sources because of its importance in achieving permanent in product associated with creativity and rooting.

\subsubsection{Synthesis in cinema}

In cinema, synthesis is the process of assembling random clips of different shots or images in the form of animations or designs in order to accommodate a topic or article with different characteristics or appearances concerned with different topics and interests (Webster, , 1994, p 486). It has also been defined as representing the separate successively sequenced sections of a movie tape, picture, movie, piece of music, or a composition resulting from placing a group of pictures one next to the other separately with the aim of forming a mixture or a unique unusual product, and it represents the process that deals with a specific picture or movie (Crowther, 1995, p 753). The term synthesis procedures was introduced by relying on how they are interconnected in the compatible or divergent shots in the new production, so superficial synthesis procedures emerged, which are related to addition, deletion and fragmentation procedures, in 
addition to deep synthesis procedures, which are related to reorganize and reconfigure resulting from multiple shots in the scene. As for the synthesis nature, it has adopted several classifications, the most important of which is the adoption of an open synthesis that depends on the use of unconnected (separate) intellectual snapshots and their recombination so as to give a certain emotional or intellectual effect. Pudovkin ${ }^{1}$ points out that synthesis is not a means of telling a connected story, but rather an openness to the idea by juxtaposing shots from other fields in an appropriate way to generate new meaning. As for the other type, it is the dependence of affiliation (continuous) synthesis: in this text components are successively arranged without interruption, retrieval or anticipation, each part continues the previous part according to precedence. Here the tuner is concerned with the formula of continuity in time and space by entering all the variables within the same framework, where the past has the same weight as looking to the future (Mast and Cohen, 2004, p 105).

We conclude from above the possibility of depending apparent or deep synthesis procedures. In addition, concepts emergence of synthesis related to both the entity investing in the synthesis on one hand, and the new product on other hand, which may achieve the link between different fields or achieving the time process or work on restructuring and organizing the components of the structure, or being working within the intellectual rules which achieve a qualitative leap in achieving the purpose and content.

\subsection{Synthesis concept in contemporary architecture}

After synthesis concept was dealt within the most relevant fields "art and cinema", previous architectural studies on this topic will be discussed in this axis. As for the selection of previous studies, as the scarcity of literature that dealt with the concept of synthesis in a specialized manner, specifically in contemporary architecture, it will be based mainly on the studies that dealt with the concept in architecture in an implicitly, in addition to the studies that included a reference to the concept of synthesis within Contemporary architectural eras (modern, postmodern, deconstructive, and digital architecture), in order to determine the specificity of the synthesis formula in it and put forward the aspects associated with each of them, in order to determine the research problem and its objectives, and then put forward the approach that will be adopted in the research.

\footnotetext{
1 -Vsevolod Illarionovich Pudovkin (1893-1953) was a Soviet film director, screenwriter, and actor who developed influential montage theories. He was awarded the title of People's Artist of the USSR in 1948 (https://www.britannica.com).
} 


\subsection{1 (Hartoonian, 2017) - General Study}

Hartoonian explains that synthesis is one of the solutions proposed in contemporary architecture, through its possibility to go back to the past and rediscover the elements to which it belongs and synthesize them into models that fit the requirements of the present time (Hartoonian, 2017, p 7). The study presents the intended goals of dependence synthesis in the new architectural products, as it indicates that it is a formula that aims to create change in a way that preserves historical communication and links the past, present and future (time process) and ensures the generation of products bearing meanings and connotations with a temporal depth, meaning that synthesis is a process Through it, the old meanings can be pulled back to add other new meanings to the fore. It is a formula that ensures the preservation the chain of interrelationship between the past and the future through the present and aims to achieve permanence and communication with history (Hartoonian, 2017, p 127). In separate paragraphs, the study provided implicit mentions to other aspects represented by sources type invested and the reliable procedures for synthesis. The study was satisfied with describing the primary sources invested in synthesis as primitive models belonging to ancient civilizations. It referred to the procedures adopted for synthesis that include reproduction, reassembly and reorganization, but the study did not clarify the nature of these procedures, nor the detailed aspects associated with them (Hartoonian, 2017, p 155-169).

\section{Second: Studies that dealt with synthesis within contemporary architectural eras}

\subsection{2 (Frampton, 2020) - Modern Architecture}

The study implicitly proposed synthesis as one of the formulas to achieve permanent in modernity architecture. With regard to this formula, the study was distinguished by its presentation of many different aspects related to synthesis. It dealt with the source invested for synthesis, which was clarified that it includes direct formal elements investment belonging to fields outside architecture field represented by technology, such as the ocean liner model, which Le Corbusier used to adopt as a primary source for his new models. Frampton points out that elements belong outside architecture are invested and absorbed in architecture while providing them with what they lack of symbolic content, and this confirms the possibility of investing elements that do not It belongs to architecture as primary sources (Frampton, 2020, p 3-7). Also, the study presents in another paragraph in a brief the procedures adopted for synthesis, as it indicated that 
synthesis represents a formula that includes a reinterpretation of references (primary sources), but the study did not clarify the nature of these procedures, nor the detailed aspects associated with them, even in brief (Frampton, 2020, p 313).

\subsection{3 (Gura, 2017) - Postmodern}

The study provided brief indications about some aspects related to the synthesis formula, as it clarified a relationship between structure and synthesis, confirming that there are no combinations that do not produce new shapes and structures (Gura, 2017, p 11). On the other hand, the study referred to the type of sources invested for synthesis, describing them as patterns belonging to history, as Gura indicates that synthesis does not represent the embodiment of a certain thought only, but also means the opportunity to go towards the history of architecture and select patterns from them for adoption as primary sources for the synthesis process (Gura, 2017, p 11). Then the study referred briefly to another aspect represented in the overall essence of source investment, as Gura explains the possibility of adopting a certain element as part of a total composition, it may be a pillar, column or any other element and implementing it as a primary source, but taking into consideration its original links (the relationship of the element with the rest Elements at the level of the part, and the relationship of the main ideas associated with the original source at the level of the whole).

Finally, the study presented the intended goals of dependence synthesis, as Gura indicates that it is a means through which communication with history can be achieved in a manner that shows the past important equal in importance to the present and the future (Gura, 2017, p 62). Here, Gura links synthesis between synthesis and the achievement of permanence, as he says that the synthesis process is not a tool for permanence, but represents permanence itself (Gura, 2017, p 265).

\subsection{4 (Eiesnman, 2003) - Deconstructive Architecture}

The study provided an explanation of intended meanings nature for its adoption of the synthesis formula. As the study clarified the need to focus on the textual level of meaning, which will achieve continuity and pluralism in understanding the architectural production, and therefore there is a change from the metaphorical symbols, which Eisenman knew to the signs that distinguish the differences through its structural relationships and not its formal or figurative relationships (Eisenman, 2003, p 2). Eisenman also emphasized that new concepts don't cancel out previous ideas and data and cannot forcibly contain 
them at the same time, but they appear simultaneously with them, and this allows to move away from deliberative solutions in architectural production methods. During its presentation of the idea of the rhetorical form in architecture, the study provided a brief reference to the side regarding the situation regarding the presence of the approved reference (the original source) in the final product, as the original source appears in difference case between presence and absence (Eisenman, 2003, p 29-32).

\subsection{5 (Abel, 2017) - Digital Architecture}

The study presented synthesis as one of the methods that represent an application of new concepts and principles, which adopt a method that includes flexible movement between traditions on the one hand and contemporary on the other hand, and attention to complexity on its deep expressive levels. Other fields such as (literary theories and more recently scientific theories that concerned the general nature of complexity itself) (Abel, 2017, p 44-52). The study touched on the methods of synthesis adopted within this stage in architecture, as the study emphasized the occurrence of a revolution in the ways and methods of architecture production, as it included complexities in addition to the apparent levels, other more profound levels (intellectual) that worked on forming the new environment and was able to add meanings to it in consistent with twenty-first century data. The study emphasizes the importance of achieving integrative synthesis thinking between the two poles, exploiting the formation and the executive capabilities to embody those concepts and theories that add new meanings (meanings plurality) (Abel, 2017, p 160).

\section{After discussing the most important features of the previous}

literatures, It is clear that the studies differ among themselves in presenting most of the aspects related to the synthesis formula, as each study presented a set of aspects that are related to the contemporary architectural production, but differ from the aspects presented in other studies, which led to the dispersion and limitations of knowledge and the inability to formulate specific and accurate items that clarifies Synthesis as a formula in contemporary architecture. Therefore, the research problem arose with "knowledge lack about synthesis essence that achieves the permanent of contemporary architectural production." While research goal was: to clarify "the specificity of the synthesis that achieved the permanently of contemporary architectural product in terms of its essence and basic components." To achieve the goal of the research, a method will be adopted that includes the following steps: - 
1- Formatting comprehensive theoretical framework that includes precise and clear items through which the initial hypothetical scenarios that explain synthesis formula in study can be put forward.

2- Applying the framework of projects that represent the products of contemporary architecture, according to the final conceptions of the theoretical framework and application results.

\section{The second axis: Theoretical framework formatting}

This axis presents several paragraphs that present most important items that shows the essence of the synthesis adopted in the contemporary architectural production, which was represented by source type of invested in synthesis, the spatio-temporal affiliation of the source, the harmonic and total nature of the source, and its apparent and essential characteristics, as follows:

\subsection{Invested source type}

Colquhoun's study indicated to invest typical building models sources, such as religious and historical industrial buildings, and others (Sykes, 2012, p 63). He also raised the importance of investing resources that included types representing previous styles belonging to the history of architecture, Fig.1, which may be styles of architectural traditions or specific models and items that represent solutions to similar problems (Colquhoun, 2009, p 43). Rossi points out that the sources invested for synthesis represent architectural constants that can never be mistaken, and communication with them must be preserved as they represent the meaning and essence of architecture, as he explains that the column and the base, for example, are elements belonging to architecture history and they are parts that represent a document of time and a reminder of what remains Including, as they are symbols that can be considered constants in architecture, and they are parts that become, according to the synthesis, a source that can be converted to generate many other buildings (Rossi, 2010, p 21).

On the other hand, Colquhoun touched on the possibility of investing types that belong outside architecture field, Fig.2, such as industry and technology, and adopting formal formations that reflect nature and of plants and animals' forms (Colquhoun, 2009, p 77). Jenks also pointed out the possibility of investing some kind of concepts outside the field of architecture, such as science, at the level of modern scientific concepts and theories, and investing in arts such as music, 
painting, and basic organization of paintings, in addition to philosophy and economics.

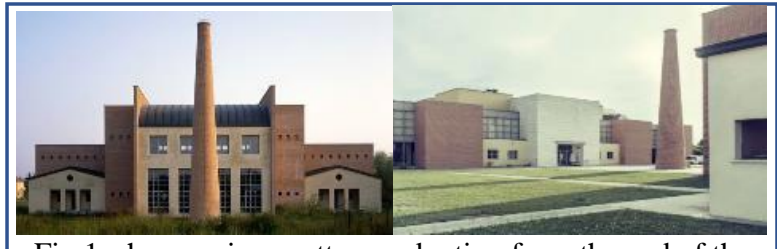

Fig.1. shows prison patterns adoption from the end of the eighteenth century in City Hall project by architect Aldo

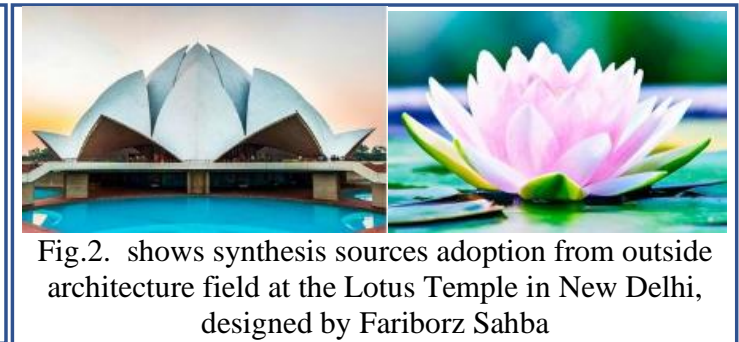
designed by Fariborz Sahba

\subsection{The spatiotemporal affiliation of synthesized resource}

Colquhoun pointed out the possibility of investing resources belonging to the present time, and this do not necessarily bear affiliation to a specific place, as they were seeking to achieve global architecture related to human needs such as sustainable architecture (Colquhoun, 2009, p 63). While Vidler mention to the possibility of investing resources belonging to a distant previous period, which was emphasized by the pioneers of postmodern architecture and classical architecture, and he referred to spatial affiliation as local resources belonging to the same place or city, and with reference frames belonging to one field, which is architecture. On the other hand, Able raised the possibility of investing sources belonging to recent periods of time, or belonging to the present time. He also indicated the possibility of investing sources with divergent spatial affiliations and bearing different frames of reference that may have local references or reflect the neighboring context (Abel, 2017, p 161).

\subsection{The harmonic nature of synthesized source}

Baker indicated the possibility of adopting a formal compatibility relationship with the sources invested from outside architecture (Baker, 2003, p 162). An example of this is investment Chinese architectural designer, Ieoh Ming Pei, the shape of the ablution fountain, which was established in the thirteenth century in Ahmed Ibn Tulun Mosque in Cairo, in the design of the Museum of Islamic Art in Qatar, in addition to adopting a semantic compatibility relationship with the invested resources, such as the adoption of the white color to reflect divine peace in project, Fig.3, (www.dezeen.com/2008/12/02/museum-of-islamic-art-by-impei/). On other hand, Baker points to the emergence of a formal antagonism relationship with resources invested in architecture (Baker, 2003, p 168). For example, the Chinese-American designer Pei relied on the Egyptian pyramid in designing Louvre Museum pyramid in France, but making it transparent not solid 
by adopting glass, Fig.4, (www.archdaily.com/88705/ad-classics-le-grandelouvre-i-m-pei ).

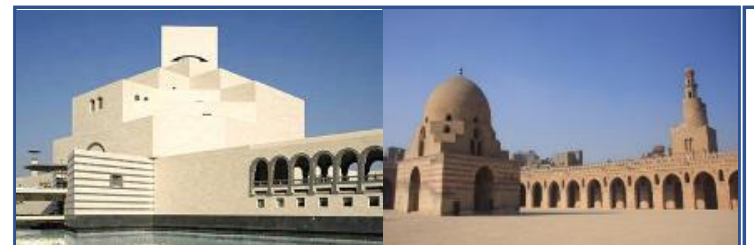

Fig.3. shows formal and semantic compatibility in the Museum of Islamic Art in Qatar (/www.dezeen.com)

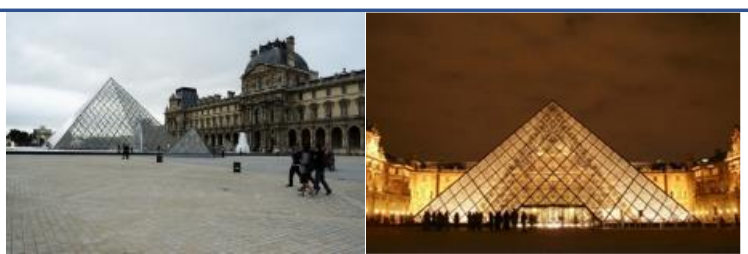

Fig.4. shows of formal contrast in the Louvre Pyramid Project, by designer leoh Ming Pei, France

\subsection{The overall nature of the synthesized resource}

Ungers mentioned the possibility of synthesis with primary sources at the "whole" level, Fig.5, to represent configurations that reflect overall figure of the source investing in synthesis (Jacob, 2018, p 94). In addition, Sykes points to the possibility of investing selected patterns from the city's past at the partial level, Fig.6, to transform them into new entities that continue with the city's past, since the selection of a pattern and its re-composition within new contexts does not mean cutting that shape or stripping it of its original meanings associated with it, whether it is historical, social or other, but with the meanings that the stereotyped form carries, it can be invested as a key to generating new meanings (Sykes, 2012, p 280-283).

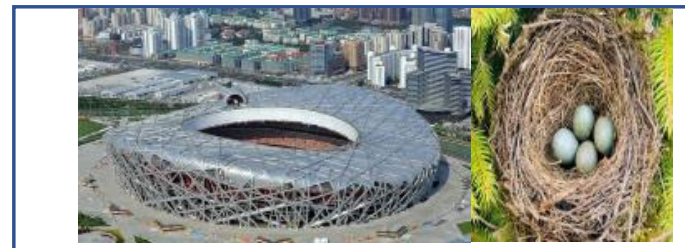

Fig.5. shows the adoption of formative synthesis in the Beijing National Sports Stadium project by Architecture Herzog

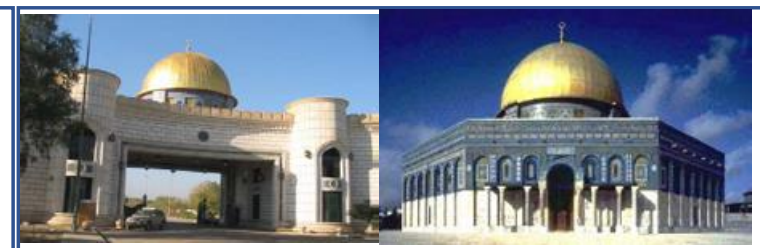

Fig.6. shows the adoption of partial synthesis in the Republican Palace Gates project in Iraq

\subsection{Synthesized resource Characteristics}

Colquhoun touched on the possibility of adopting procedures that include changing apparent characteristics of synthesizing source, such as investing primary sources representing architectural traditions, as adopting the shape and rhythm of windows in building facades in "classical architecture" to be changed from windows with a repeating rhythm to windows with a single rhythm in "modern architecture" (Colquhoun, 2009, p 51). On other hand, Jencks pointed to the possibility of adopting fixation procedures at external properties level, as their apparent properties were fixed as a total composition, to appear clearly in the final product. An example Frank Gehry's adoption of fixation procedures for 
apparent properties in its original overall composition, such as adopting the boat shape in the Guggenheim Bilbao Museum in Spain, with the aim of providing a friendly image to the recipient Fig.7. (Jencks, 1995, 77). Besides that, Able indicated the adoption of fixing procedures for essential characteristics at basic concepts level invested from the original source in synthesis, such as concept adoption of self-similarity between the different symbolic forms and the building's special functions, for example, investment of musical notes and function nature of the Disney Hall for concerts, Fig.8, and the adoption of bird formation to reflect the peace concept in the project TGV station by architect Calatrava (Abel, 2017, p 111).

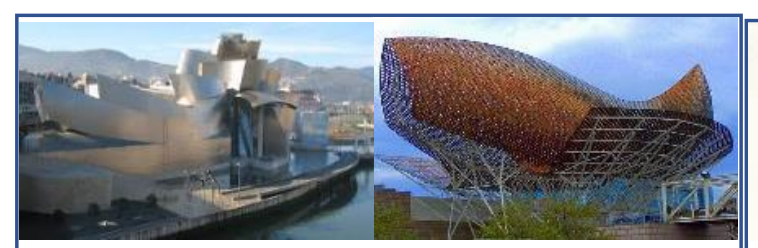

Fig.7. shows Fixing Phenomenological Characteristics of Synthesized Source in the Fish Building in Barcelona, and .Boat Shape in the Guggenheim Museum, by Frank Gehry

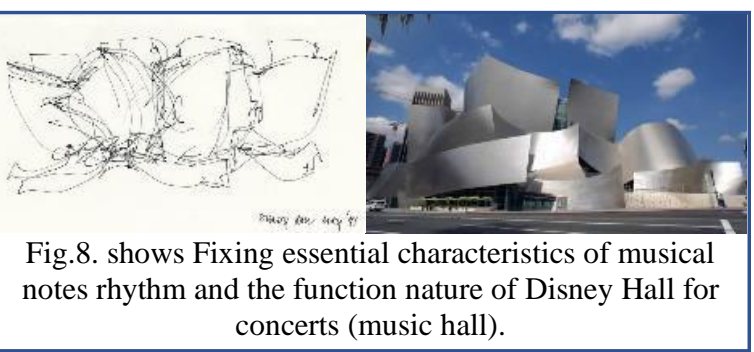

concerts (music hall).

\section{Practical study}

This chapter aims to apply theoretical framework items that was reached in the previous chapter as a last procedural step to solve the research problem. The chapter chose the items that achieves the research objective and coded them for measurement, then selects research samples for application, and is represented by architectural projects in three contexts (Foreign, Arab, local), to be analyzed according to the items of elected theoretical framework and according to the designer's vision, according to description of architectural specialists as recipients and not As the general public, being one of the most recent projects dating back to the second decade of the twenty-first century, to ensure impartiality of researcher and to ensure the highest credibility and the possibility of generalizing the final research conclusions.

\subsection{Research samples selection for the application}

\subsubsection{Foreign Projects Analysis: Oculus Mass Transportation Project / Designed by Santiago Calatrava / 2016}

It is a public transit center at the site of September 11, 2001 attacks on the World Trade Center towers. The idea of the building's shape can be summarized as an image of "a bird liberating from the hand of a child". The designer made the building a bird shape that contradicts the proposed context of the towers and 
is completely different from what surrounds it. Therefore, the station represents an intermediate building that humanizes the general context of the giant towers .In addition, when a person is inside the station, he feels that it is wide and large, but when he approaches it, he feels that it is less because of the staircase system that leads you to lower levels, as the facade has a slope that appears to grow towards the ground (www.archdaily.com). The building is a monument to life to create a more humane environment, as it bears witness to belief that this tragedy can be overcome, "a symbol of the camaraderie of the American people and a gift to society" rather than terror and devastation. In addition to how to deal with the design of the transport hub, in addition to the inclusion of a context different from the prevailing context in the city, Fig.9. (https://www.architecturaldigest.com/).

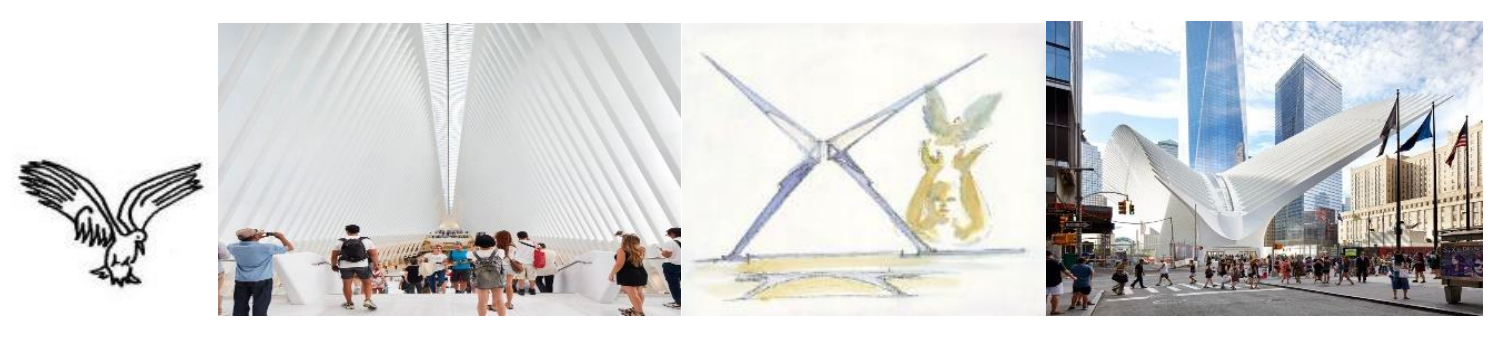

Fig.9. shows synthesis formulas in the Oculus Mass Transportation Project by Calatrava, USA, 2016

\subsubsection{Barjeel Center Project for Modern Arab Art in Sharjah, UAE - Cell Studio, 2019}

Project design idea is to show the role of art as a storyteller. Modern Arab Art Museum, Barjeel, reflects the Arab identity in a contemporary way, as two frameworks are combined, geometric (solid) to reflect the traditional aspect of architecture and textured (wavy) simulating the flow of Arabic lines (Arabic calligraphy) as shown in Figure (4-6) (www.amazingarchitecture.com/).

A Process of deletion and addition was also made to create the internal spaces, by designing a public square inspired by the idea of ancient Arab arena for cultural and artistic events. Spatial experience in project was expressed through the transition from outer courtyard within the galleries that are visually or tacitly connected to the inner courtyard and gradation levels to reach the highest point open to the sky to overlook the courtyard and to see the project completely reflecting the whole picture in the art (https://tamayouz-award.com/). A contemporary interpretation of the Barjeel - the Arabic name for wind towers - which is traditionally used in the Gulf region to provide ventilation in hot desert climate, has been interpreted as skylights while also contributing to the natural passive ventilation of the interior spaces, giving sustainable characteristics to the 
project (https://tamayouz-award.com/). Tamayouz Award judges say that this project represents an original and exciting design that blends history and contemporary and addresses the blending of many other issues such as local and global, traditional and contemporary while linking the past to the future in addition to present an idea that clearly shows Arab art at spaces level. A very powerful landmark and iconic image, it fits the context perfectly and cannot be placed anywhere else, Fig.10. (https://tamayouz-award.com/).

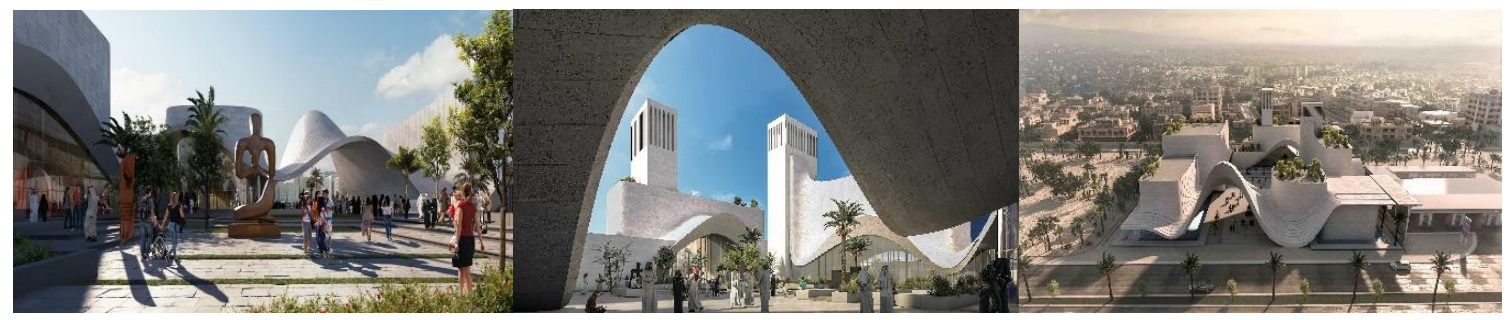

Fig.10. shows synthesis formulas at Barjeel Center for Modern Arab Art in Sharjah designed by Cell Studio, United Arab Emirates, 2019.

\subsection{3 local projects Analysis: General Secretariat building of the Council of Ministers in Iraq / 2012}

Al-Haboubi focused on expressing the values of freedom and infinity in the building, saying that resorting to references and architectural forms cannot achieve a unique form, unlike art forms. Resorting to art represents the way to express in a new form, but it remains continuous with its deep roots, and for this reason, it focused on building an architectural language from many codes to express those values (https://www.archdaily.com/). To achieve this, Al-Haboubi relied on the importance of weaving the relationship between solid and void, down to a hybrid form linking the geometric shape rigidity to the void formed from the symbol of infinity invented by the early Sumerians, to be developed into the concept of the Iraqi constitution, free and infinite, the cylinder seal engraved on its surface all the features of the Iraqi past that brought it to the present and directed it towards the future, and for this the unique language was produced. Also, mixing cuneiform language, historical symbols and decorations hybrid language that conveys a distinctive Iraqi flavor that you can never miss when seeing the building in a new language which makes the building belong to its era and at the same time conveys and expresses the originality of the place to which it belongs. The building was described as having shortened tens of thousands of years for the original Iraqi history and its legacy, but it was not captive to narrow religious or nationalist perceptions. The ancient pedicures in a contemporary style through advanced treatments and materials, Fig.11. (www.archdaily.com). 


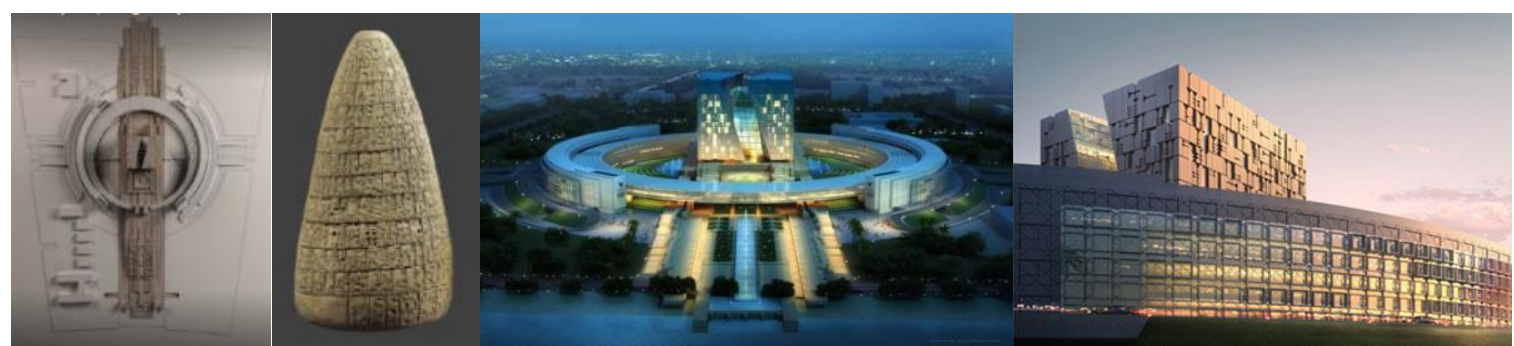

Fig.11. shows synthesis formulas in General Secretariat building of Ministers Council, Manhal Al-Haboubi, 2012.

\subsection{Applying measurements items to the projects of practical study:}

After presenting detailed description of the elected projects, the variables of the theoretical framework items will be measured on the practical study projects using comparative descriptive analysis method between elected projects. variables were measured by specifying values ranging from $0-1$, as $(0=$ unrealized value, $1=$ realised value) as in the table (1).

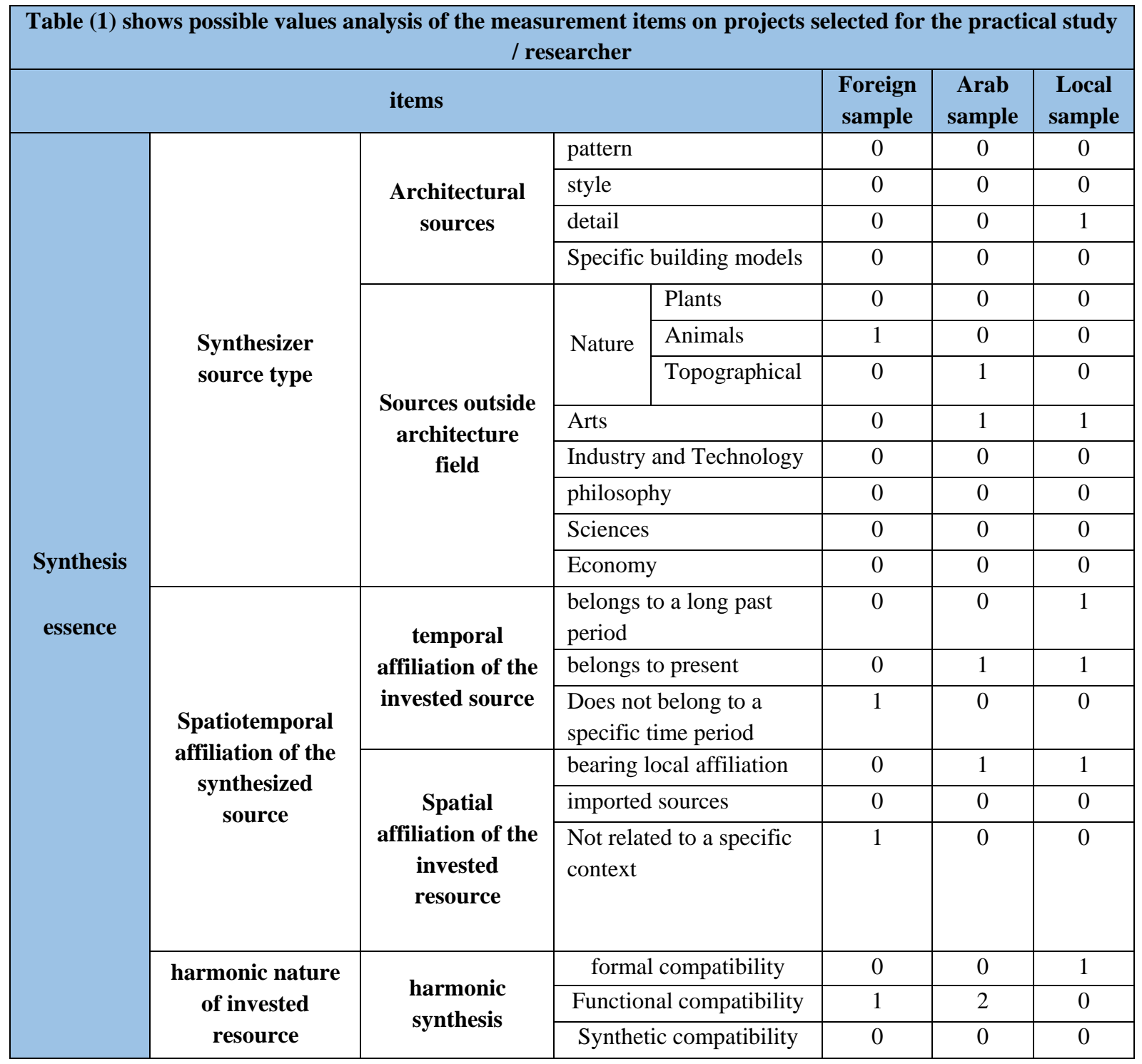




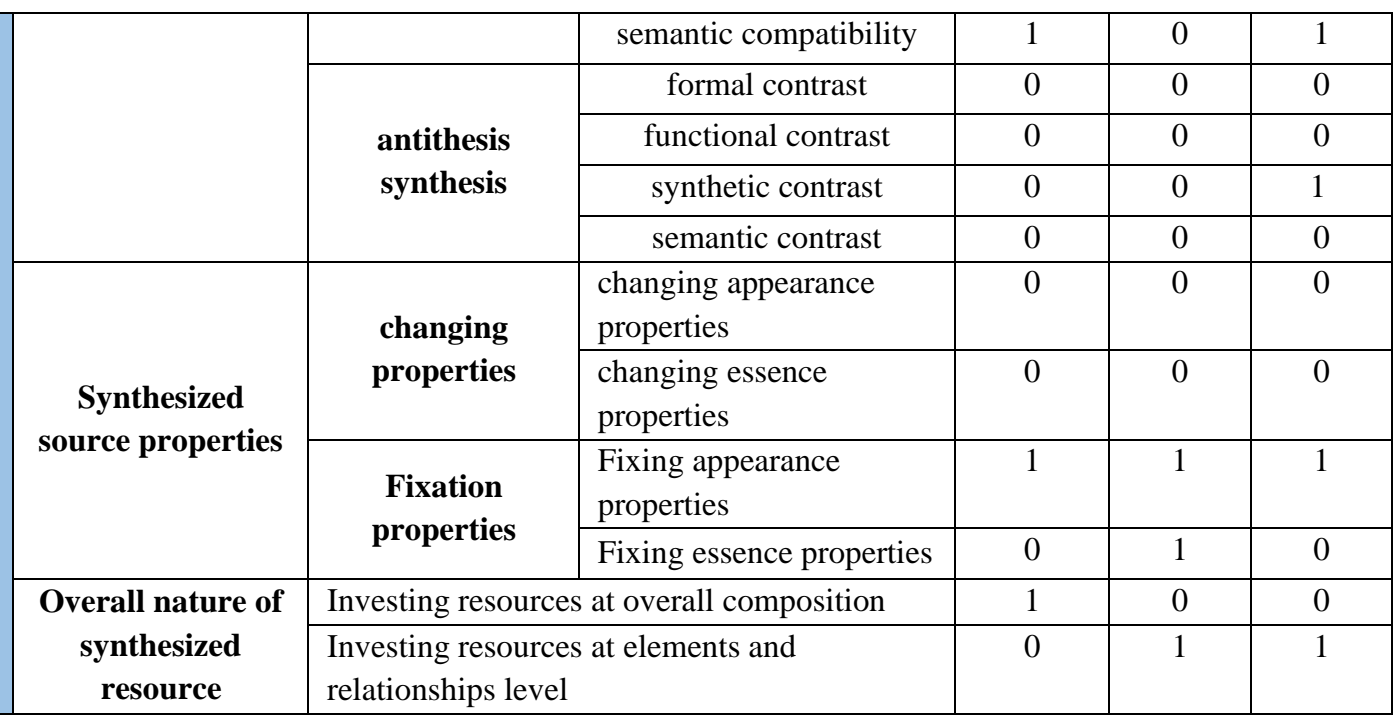

\section{Conclusions:}

- It was possible to extract the definition of Synthesis as a comprehensive formula to achieve permanence in architecture - as an intentional act - that ensures the achievement of new architectural products while preserving the relationship with the assets (synthesized original sources), by adopting certain procedures regarding different levels of original invested resources, according to the determinants - standards and objectives meets the basic requirements of the new case data.

- The objectives of adopting synthesis in the architectural production lie in three main objectives: general, private, and subjective. The general objectives were to achieve renewal, innovation and adaptation to the emerging changes, in addition to renew production methods in architecture, and moving away from the deliberative limits in it. As for the special goals, they were to reflect developments in industry field and technology on architecture, in addition to communicating with history without literal repetition error for the data of the past, and an attempt to open up towards other scientific fields, while some sought to achieve openness towards other scientific fields. Finally, with regard to the subjective goals, which are represented in providing a familiar image to the recipient, and increasing the possibility of the user's interaction with the architectural product, by dividing the project into the largest possible number of parts, each part linked to a specific mental image and then re-installing the parts, which generates multiple mental images that can be associated with each The types of symbols, ideas, and distinct events in a person's life who wish to recall them through architecture.

- One directions of synthesis formula is that it ensures the transfer of specific formal items (ship model) for example, linked to contexts outside architecture 
field such as industry and technology (synthesis in horizontal direction), and its adoption as primary sources for synthesis process which submit to a series of synthesis procedures while maintaining the original return, therefore the final product for synthesis process bears characteristics associated with formal items belonging to contexts outside architecture.

- There is another direction in adopting synthesis in architecture is the importance of communicating with previous data, whether they are data that represent types belonging to architecture history or data specific to the architecture type of as a direct previous stage (synthesis in vertical direction), communicating with history and rejecting the idea of returning to the past in ways based on moving away from the deliberative limits in the methods of architectural production, and moving away from literal repetition of data of the past, and its adoption as primary sources for new architectural generation product in which the past shows an equal weight in importance to the present and the future.

- A third trend emerged in adopting synthesis as a formula to achieve permanence in architectural production on several levels (vertical and horizontal synthesis), not through communication with previous data of the source that was synthesized only, but rather to achieve openness towards other scientific fields and the employment of modern ideas and concepts, as synthesis is a formula that guarantees dealing with discoveries and scientific theories then balancing them with architectural traditions in a manner that includes investing data at ideas level and concepts derived from fields outside architecture, not data at the level of formal items and their application in production processes in architecture. This ensures the production of rich systems that carry free connotations through which the process as a whole can be described as creativity.

- plural synthesis represents a holistic trend, by combining a large number of data from different environments, taking a refracted line that does not represent any boundaries within which the form or content is distinguished, but it zigzags through things leading it sometimes to (non-content) where it vanishes itself, and sometimes new models appear that rise to a future state, and therefore they build the event instead of depicting it.

- Achieving permanence determinants were represented in making communicative feature between individuals within a particular culture or civilization, and balancing belonging search as much as openness and contemporary search, which leads towards creativity and innovation. As creative innovation is achieved by moving away from origin point in a 
communicative manner, which ensures not to stop at changes limits only because they lead to discontinuation.

- International architecture emphasizes investing sources from outside architecture, as a kind of response to the changes accompanying the technological revolution and developments in the surrounding fields, while Arab and local architecture focuses on investing resources from architecture field to produce buildings that are linked to their previous architectural origin.

- Global architecture emphasizes investing resources that do not belong to a precise time in an attempt to achieve international architecture that is not restricted to a specific time. While the Arab and local architecture focus on investing resources belonging to a recent period linked to its heritage, which go back to its cultural roots and belong to a long time period.

- Arab and local architecture emphasizes investing resources at the part level because of its importance in achieving a state of pluralism in meanings while achieving communication with previous architectural assets. As for global architecture, the greatest focus was on investing resources at the whole level to clarify the meaning of the source for the investor from outside the field of architecture and its synthesis with it.

- Architectural products emphasize synthesis formula adoption linked to a compatibility relationship with the source that is tuned, but it varied in detail to reflect the formula specificity, as the international and Arab samples emphasized the importance of achieving a formal harmonic synthesis, because of their belief to achieve a state of explicit harmonic for the synthesized product, while local samples, in addition to the above, sought to Achieve a state of semantic compatibility in order to invest in the essential aspects and make the product more rich and permanently.

- Synthesis formula focused on shifting from figurative meaning (figurative formal relationships, figurative symbols) to synthetic meaning (synthetic relationships of ideas and concepts derived from architecture field and beyond) through sign language and free meaning (Basic meanings multiplicity).

\section{References}

- https://www.almaany.com/

- Omar, Ahmed Mukhtar, A Dictionary of Contemporary Arabic Language, World of Books, Cairo, Egypt, 2008

- https://www.britannica.com/

- https://dictionary.cambridge.org/dictionary/english/synthesis 
- https://www.merriam-webster.com/dictionary/synthesis

- Alsaed, Abdullah, "Experimenting with Forming Democracy", published in Damascus University Journal of Science and Engineering / Refereed Scientific Journal / Volume 17 - Issue Two -, 2001, pp. 22-25

- Deleuze, Gilles "What is Philosophy", translated by Mut'a Safadi, the Arab Cultural Center, Beirut, 1, 1997, p. 150/156

- Webster, Mariam, Webster's Study Dictionary, Librairie du Liban Publishers, 1994, p 486.

- Crowther, Jonathan, Oxford Advanced Learner`s Dictionary of Current English A S Hornby, Oxford University Press, 1995, p 753.

- Mast and Cohen, Film Theory and Criticism: Introductory Readings 6th Edition, 2004, p 105.

- Hartoonian, Gevork, Time, History and Architecture: Essays on Critical Historiography (Routledge Research in Architectural History) 1st Edition, Kindle Edition, 2017, p 7.

- Frampton, Kenneth, Modern Architecture: A Critical History (World of Art), Thames \& Hudson; 5th edition Kindle Edition, 2020, p 3-7.

- Gura, Judith, Postmodern Design Complete: Design, Furniture, Graphics, Architecture, Interiors, Thames \& Hudson, 2017, p 11.

- Eisenman, Giuseppe Terragni: Transformations, Decompositions, The Monacelli Press, 2003, p 2.

- Abel, Chris, Architecture and identity, Routledge; 3rd edition, 2017, p 44-52.

- Sykes, A. Krista, Constructing a New Agenda: Architectural Theory, Princeton Architecture press, USA, 2012, p 63.

- Colquhoun, Alan, Collected Essays in Architectural Criticism, University of California, Black Dog Pub., 2009, p 43.

- Rossi, Aldo, A scientific Autobiography, opossitions books, the Mit Press Cambridge, London, 2010, p 21.

- https://www.dezeen.com/2011/06/10/riverside-museum-by-zaha-hadidarchitects/

- Baker, Geoffrey H., Design Strategies in Architecture: An Approach to the Analysis of Form 1st Edition, Kindle Edition, Taylor \& Francis; 1st edition, 2003, p 162.

- https://www.dezeen.com/2008/12/02/museum-of-islamic-art-by-im-pei/

- https://www.archdaily.com/88705/ad-classics-le-grande-louvre-i-m-pei 
- Jacob, Sam, Oswald mathias ungers: dialectical principles of design, Architectural Association School of Architecture, Taylor \& Francis for publication, UK, 2018, p 94.

- Jencks, Charles, The Architecture of Jumping Universe, Academy Edition, London, 1995, 77.

- https://www.archdaily.com/783965/world-trade-center-transportation-hubsantiago-calatrava

- https://www.archdaily.com/783965/world-trade-center-transportation-hubsantiago-calatrava

- https://www.architecturaldigest.com/story/santiago-calatrava-explainsdesigned-oculus-for-future-generations

- https://www.amazingarchitecture.com/museum/barjeel-museum-for-modernarab-art-in-sharjah-uae-cell-studio

- https://tamayouz-award.com/rifat-chadirji-prize-barjeel-museum-formodern-arab-art-in-sharjah-winners-announcement/

- https://www.behance.net/gallery/89836271/BARJEEL-ART-MUSEUMRIFAT-CHADIRJI-PRIZE

- https://tamayouz-award.com/rifat-chadirji-prize-barjeel-museum-formodern-arab-art-in-sharjah-winners-announcement/

- https://www.archdaily.com/185127/infinite-free-iraqi-constitution-proposalmanhal-al-habbobi?ad_source=search\&ad_medium=search_result_all

- https://www.archdaily.com/185127/infinite-free-iraqi-constitution-proposalmanhal-al-habbobi?ad source=search\&ad medium $=$ search result all

- https://www.archdaily.com/185127/infinite-free-iraqi-constitution-proposalmanhal-al-habbobi?ad_source=search\&ad_medium $=$ search_result_all

- https://www.archdaily.com/185127/infinite-free-iraqi-constitution-proposalmanhal-al-habbobi?ad_source=search\&ad_medium=search_result_all 